УДК 541.67

Коваленко О.А., Рагуля А.В.

Інститут проблем матеріалознавства імені I.М. Францевича НАН Украӥни, м. Київ

\title{
ОСОБЛИВОСТІ ДОПУВАННЯ НАНОДИСПЕРСНОГО ПОРОШКУ ТИТАНАТУ БАРІЮ 3 МЕТОЮ ОТРИМАННЯ СЕГНЕТОЕЛЕКТРИКІВ-РЕЛАКСОРІВ 3 РОЗМИТИМ ФАЗОВИМ ПЕРЕХОДОМ
}

Проведений огляд літератури допантів та методів допування нанодисперсного порошку титанату барію з метою отримання сегнетоелектричних матеріалів 3 релаксорною поведінкою і розмитим фазовим переходом, зокрема, досліджені елементи для згладження температурної залежності діелектричної проникності та визначений найбільи доцільний метод отримання стехіометричного допованого нанодисперсного титанату барію з високою продуктивністю і економічністю, а також з відсутністю вторинних фаз.

Проведенный обзор литературы допантов и методов допирования нанодисперсного порошка титаната бария с иелью получения сегнетоэлектрических материалов с релаксорным поведением и размытым фазовым переходом, в частности, исследованы элементы для сглаживания температурной зависимости диэлектрической проницаемости $и$ определен наиболее целесообразный метод получения стехиометрического допированного нанодисперсного титаната бария высокой производительностью и экономичностью, а также с отсутствием вторичных фаз.

Literature review of dopant and methods of doping barium titanate nanopowder to obtain ferroelectric materials with relaxor behavior and diffuse phase transition was conducted. Particularly, elements for smoothing the temperature dependence of the dielectric constant was characterized and the most appropriate method for stoichiometric doped barium titanate nanopowder with the lack of secondary phases, high performance and efficiency was determined.

\section{Ветуп}

Керамічні діелектрики складають важливу частину елементів сучасної електронної техніки [1], зокрема конденсаторної індустрії, де за рахунок своїх унікальних властивостей найширшого використання набув титанат барію. 
Оскільки розвиток сучасної електроніки передбачає зменшення розмірів елементів одночасно зі збереженням основних технічних, експлуатаційних властивостей його компонентів, актуальним є використання в технології виробництва діелектриків порошків нанорозміру. Це дозволяє за рахунок суттєвого ущільнення частинок в об’ємі та за рахунок особливостей поведінки нанорозмірних систем кардинально зменшити розміри і значно покращити характеристики кінцевого продукту. Більше того, дрібна морфологія дозволяє знизити температуру спікання і використовувати менш дорогі електроди.

Крім того, в останні роки активно досліджується біосумісність нанодисперсних порошків титанату барію та можливість їх використання в сфері наномедицини, зокрема, в тканинній інженерії, стимуляції клітин, терапії раку, доставки лікарських засобів тощо [2].

Основними критеріями ефективного використання даного діелектричного матеріалу є збереження таких експлуатаційних властивостей, як висока діелектрична проникність, температурна стабільність, низькі діелектричні втрати при максимальній діелектричній міцності і питомому об’ємному опорі, а також висока стійкість до електрохімічного старіння.

Оскільки забезпечення ефективної та надійної роботи діелектрика в широкому температурному інтервалі обумовлюється характером фазового переходу в точці Кюрі, то актуальним на сьогоднішній день є отримання допованих сегнетоелектриків-релаксорів 3 розмитим фазовим переходом в даній точці 3 метою згладжування температурної залежності діелектричної проникності.

\section{1. Релаксорна поведінка сегнетоелектричних матеріалів}

Сегнетоелектричні матеріали типу перовскіту зазвичай характеризуються високими значеннями діелектричної проникності. Однак існують типи сегнетоелектриків так звані сегнетоелектрики-релаксори, які останнім часом заслуговують на особливу увагу у зв’язку 3 унікальними діелектричними властивостями, які ще досі не достатньо добре вивчені. Особливостями релаксорної поведінки $є$ широкі піки температурної залежності діелектричної проникності, різниця в значеннях температур максимуму дійсної і уявної складової діелектричної проникності, а також не виконання закону Кюрі - Вейса за температури, близької до температури максимуму дійсної складової діелектричної проникності, яка залежить від частоти вимірювання, але не пов'язана 3 фазовим переходом [3].

Згладження температурної залежності можливе за умови розмиття фазового переходу і розширення темпераутрної залежності діелектричної проникності за рахунок ефекту стиснення (Pinching effect) [4], тобто “сплющення” трьох фазових переходів (ромбічно-орторомбічних (Р-O), орторомбічно-тетрагональних (O-T), тетрагонально- 
кубічних (Т-К) модифікацій) в одній точці Кюрі, що, однак, призводить до суттєвого зниження діелектричної проникності.

Розмиття фазового переходу відбувається за рахунок механічних напружень, які, власне, визначають висоту максимального значення діелектричної проникності. Для цього необхідне зменшення розміру зерен або використання гетерогенних матеріалів, особливістю яких є флуктуація композиту, що також викликає внутрішні напруження.

Одним із способів забезпечення плавності фазового переходу в точці Кюрі, тобто для згладження температурної залежності діелектричної проникності, $\epsilon$ допування сегнетоелектричних матеріалів за допомогою фазозміщувачів, інгібіторів, акцепторів та донорів, зокрема за допомогою $\mathrm{Mn}$ (II) [5], Ca (II), $\mathrm{Zr}$ (IV), $\mathrm{Pb}$ (II), а також таких рідкоземельних елементів, як $\mathrm{Nb}(\mathrm{V})$ [6], Y (III) [7] тощо.

Іншим способом послаблення температурної залежності $є$ синтез порошку 3 розмірами менше 10 нм. Зі зменшенням розмірів буде відповідно збільшуватися кількість доменів, а відтак зростати частина доменних стінок у загальному об'ємі, в результаті чого буде підвищуватись напруженість частинок i, як наслідок, відбуватися розмиття фазового переходу. При цьому зі зростанням доменних стінок, які входять у загальний вклад відносної діелектричної проникності, буде зростати діелектрична проникність.

Однак питання відносно впливу розміру частинок на релаксорну поведінку сегнетоелектрика суперечливе. 3 одного боку, зі зменшенням розміру зменшуються сегнетоелектричні домени, внаслідок чого в матеріалі зростає кількість менших за розміром доменів, і в результаті збільшується кількість доменних стінок в одиниці об'єму, що веде до зростання діелектричної проникності. 3 іншого боку, кількість внутрішніх механічних стресів при цьому формує високоенергетичну кристалічну решітку, що веде до фазового переходу в кубічну (параелектричну) фазу, в якій втрачаються сегнетоелектричні властивості матеріалу.

\section{1. Допування нанопорошку титанату барію}

Недопований електрично ізольований ВТ стає напівпровідником при високій температурі (більше $1350^{\circ} \mathrm{C}$ ) або в умовах відновлюючого середовища в результаті внутрішніх дефектів, утворених кисневими вакансіями. Використання індивідуальних сполук-сегнетоелектриків в якості основи для технічних матеріалів в цьому випадку недоцільне через їх недостатньо високу діелектричну проникність і незадовільну температурну залежність [1].

Другий компонент твердого розчину $\mathrm{BaTiO}_{3}$, як правило, несегнетоелектрична сполука, при додаванні якої знижується температура Кюрі. Широко використовуються тверді розчини на основі декількох бінарних систем з ізовалентним заміщенням іонів. 


\section{2. Характеристика допантів}

Допування елементами може відбуватися за рахунок ізовалентного або гетеровалентного заміщення атомів у вузлах А і В кристалічної решітки перовскітної структури $\mathrm{ABO}_{3}$.

3 метою зміщення температури фазового переходу та згладження кривої температурної залежності діелектричної проникності в якості ізовалентних іонів вводять іони $\mathrm{Zr}^{4+}, \mathrm{Ca}^{2+}$ у вузли Ті та Ва відповідно, а в якості гетеровалентних іонів, головним чином, вводять оксиди рідкоземельних елементів, які додатково дозволяють пригнічувати ріст зерен титанату барію.

Таблиця 1.

Характеристика допантів

\begin{tabular}{|c|c|c|c|c|}
\hline & Локація & Властивості & $\begin{array}{c}\text { Оптимальна } \\
\text { кількість }\end{array}$ & $\begin{array}{l}\text { Дже- } \\
\text { рело }\end{array}$ \\
\hline \multicolumn{5}{|c|}{ Гетеровалентне заміщення } \\
\hline $\begin{array}{l}\mathrm{Nb}^{5+} \\
\mathrm{Nb}^{3+}\end{array}$ & $\begin{array}{c}\text { Октаедр } \\
\text { (вузол В) }\end{array}$ & $\begin{array}{l}\text { Донор. } \\
\mathrm{Nb}_{2} \mathrm{O}_{3} \text { розмиває фазовий перехід } \\
\text { Зміщує Тс у бік менших температур. } \\
\text { Інгібує ріст зерен } \\
\downarrow \mathrm{T}_{\mathrm{T}-\mathrm{C}}+\uparrow \mathrm{T}_{\mathrm{T}-\mathrm{O}} \text { i ТО-Р } \\
\text { Забезпечує релаксорні властивості. } \\
\text { При збільшенні Nb зростає } \operatorname{tg} \delta \mathrm{i} \\
\text { спадає } \varepsilon \text {. }\end{array}$ & $1 \%$ & $\begin{array}{l}{[6]} \\
{[7]} \\
{[9]}\end{array}$ \\
\hline $\begin{array}{l}\mathrm{Mn}^{3+} \\
\mathrm{Mn}^{2+}\end{array}$ & $\begin{array}{c}\text { Октаедр } \\
\text { (вузол В) }\end{array}$ & $\begin{array}{l}\text { Акцептор. } \\
\text { Захоплення вільних електронів } \\
\text { (компенсація заряду). } \\
\text { Зменшує } \mathcal{E} \text {. } \\
\text { Не впливає на розмір кристалу. }\end{array}$ & $0,05-3 \%$ & {$[5]$} \\
\hline $\mathrm{Y}^{3+}$ & $\begin{array}{c}\text { Додекаедр/ } \\
\text { Октаедр (вузли } \\
\text { А/B) }\end{array}$ & $\begin{array}{l}\text { Зміщує Тс в бік менших температур. } \\
\text { Сприяє ущільненню та пригнічує ріст } \\
\text { зерен. } \\
\text { Знижує діелектричні втрати. } \\
\text { Сприяє плавному фазовому переходу. }\end{array}$ & $\begin{array}{l}x<0,015 \\
(\text { A-site }) \\
x<0,059 \\
\text { (B-site) }\end{array}$ & $\begin{array}{l}{[7]} \\
{[10]} \\
{[11]}\end{array}$ \\
\hline \multicolumn{5}{|c|}{ Ізовалентне заміщення } \\
\hline $\mathrm{Ca}^{2+}$ & $\begin{array}{c}\text { Додекаедр } \\
\text { (вузол А) }\end{array}$ & $\begin{array}{l}\text { Підвищує температуру Кюрі. } \\
\text { Інгібує ріст зерен під час спікання. } \\
\text { Сприяє ефекту стиснення (Pinching } \\
\text { effect). }\end{array}$ & $25 \%$ & {$[12]$} \\
\hline $\mathrm{Zr}^{4+}$ & $\begin{array}{l}\text { Октаедр } \\
\text { (вузол В) }\end{array}$ & $\begin{array}{l}\text { Фазозміщувач. } \\
\text { Інгібує ріст зерен під час спікання. } \\
\downarrow T_{\text {T-с }} \uparrow \text { T т-о і ТО-Р } \\
\text { Сприяє ефекту стиснення (Pinching } \\
\text { effect). } \\
\text { Тс }<\text { Ткімн } \\
\text { Розширює } \mathcal{E}(\mathrm{T}) . \\
\text { За х>0,2 забезпечує дифузійний } \\
\text { фазовий перехід. } \\
\text { Надає матеріалу змішаної } \\
\text { сегнеторелаксорної поведінки. }\end{array}$ & $\begin{array}{c}13-15 \% \\
x=0,2\end{array}$ & $\begin{array}{l}{[13]} \\
{[14]}\end{array}$ \\
\hline
\end{tabular}


Зокрема, у вузли катіону Ва додекаедра в якості допанту можна вводити такі елементи, як $\mathrm{Co}^{2+}$ [8] (для компенсації заряду, спричиненого введенням іонів $\mathrm{Nb}$ ), $\mathrm{La}^{3+}$, $\mathrm{Ce}^{3+}, \mathrm{Sr}^{2+}, \mathrm{Y}^{3+}$, в результаті чого утворюються вакансії Ті. В локації катіону Ті октаедру можна вводити іони $\mathrm{Nb}^{5+}, \mathrm{Ce}^{3+}, \mathrm{Sb}^{5+}, \mathrm{Ta}^{5+}, \mathrm{Al}^{3+}, \mathrm{Y}^{3+}$, в результаті чого виникає дисбаланс заряду, утворюються кисневі вакансії і, як наслідок, зростає електропровідність матеріалу та з'являються пробої. В цьому випадку необхідно забезпечити електронейтральність гратки і компенсувати заряд за рахунок внесення в решітку іонів акцептора (наприклад, $\left.\mathrm{Mn}^{3+}\right)$.

Однак, у багатьох роботах допування гетеровалентними рідкоземельними елементами призводить не до дифундування елементів у структуру решітки (як у випадку ізовалентного заміщення), а до накопичення даних елементів на границях зерен, тобто 3 утворенням структури «ядро-оболонка». Про це свідчать значно вищі значення імпедансу на границях зерен, ніж усередині, що обумовлює також різницю діелектричної проникності [28].

В праці [1] зазначено, що у випадку однофазного твердого розчину неможливо отримати розмитий фазовий перехід з низькою температурною залежністю діелектричних параметрів, оскільки необхідно декілька кристалічних фаз з різними положеннями температури Кюрі. Формування двохфазних систем може відбуватися в умовах заміщення чотирьохвалентного металу трьох- і п’ятивалентними металами.

В кераміці зі згладженою температурною залежністю $\mathcal{E}(\mathrm{T})$, отриманою на основі гетерогенного твердого розчину титанату барію (ВТ), обидві фази реалізуються в межах одного зерна, де центральна частина - ВТ, а оболонка - твердий розчин з розмитим фазовим переходом, тобто формується «зонально-оболонкова структура». Наприклад, для полегшення спікання додають Ві. При цьому Ві не встигає прореагувати з ВТ по всій глибині і фаза, збагачена $\mathrm{Bi}$, знаходиться в поверхневому шарі, тобто утворюється зонально-оболонкова структура (ЗОС). Зі зменшенням розміру зерна збільшується повнота утворення твердих розчинів з розмитим фазовим переходом. Сегнетоелектрикам 3 ЗОС характерна наявність релаксаційної поляризації, що викликана розмитим фазовим переходом. Причому причиною розмитості є макроскопічна рівноважна неоднорідність, що пов’язана з реакціями утворення твердих розчинів., а не з флуктуацією складу.

\subsection{1. Ніобій $\mathrm{Nb}$}

Додавання іонів $\mathrm{Nb}^{5+}$ інгібує ріст зерен, зміщує фазовий перехід Т-С в бік нижчих температур, а Т-О і О-Р в бік вищих температур, за рахунок чого спостерігається так званий «ефект сплющення» (Pinching effect), при якому всі три фазові переходи 
відбуваються майже в одній точці. При цьому зміщення Т-С в бік нижчих температур можна пояснити зменшенням розміру кристалів.

$\mathrm{У}$ системі $\mathrm{BaTiO}_{3}-\mathrm{BaZrO}_{3}$ з розмірами частинок 10 - 30 мкм при додаванні $\mathrm{Nb}_{2} \mathrm{O}_{3}$ утворюється твердий розчин зі значно меншими розмірами частинок (4 - 6 мкм), що пояснюється формуванням на поверхні одної фази іншою, а це інгібує ріст зерен. Однак отриманий композит втрачає сегнетоелектричні властивості i має низькі значення діелектричної проникності. Втрату сегнетоелектричних властивостей можна пояснити руйнуванням зв'язку Ті-O-Ti, що відповідає за сегнетовластивості та стабільність тетрагональної фази, внаслідок чого відбувається зміщення Т-С. Такий розрив характерний також при заміні Ті іонами Mn.

Однак в праці [6] зазначено, що введення іонів $\mathrm{Nb}$ за рахунок донорного гетеровалентного заміщення формує дисбаланс заряду та викликає електропровідність, що підвищує діелектричну проникність. Для компенсації заряду зазвичай вводять в якості акцептору іони $\mathrm{Mn}$, які захоплюють вільні електрони і сприяють стабілізації електронейтральності решітки.

\subsection{2. Ітрій $Y$}

Внесення в решітку $\mathrm{BaTiO}_{3}$ іонів ітрію (Y) дозволяє інгібувати ріст зерен і таким чином ущільнити частинки в об'ємі. Очевидно, набуття плавного фазового переходу при допуванні іонами Y пов'язане 3 пригніченням росту зерна, що супроводжується механічними напруженнями.

$\mathrm{Y}$ може займати як вузли $\mathrm{A}$, так і $\mathrm{B}$, оскільки його іонний радіус має середнє значення між $\mathrm{Ba}^{2+} \mathrm{i} \mathrm{Ti}^{4+}[7,11]$. Причому локація $\mathrm{Y}$ в решітці залежить від співвідношення $\mathrm{Ba} / \mathrm{Ti}$ і не залежить від кисневого парціального тиску. Заміщення іонами Y іонів Ва в Авузлах обумовлює утворення вакансій Ті. При заміщенні іонів Ті у В-вузлах формуються кисневі вакансії, що призводить до появи напівпровідникових властивостей.

\subsection{3. Манган Mn}

Валентний стан іонів мангану (Mn) дозволяє захопити вільні заряди в діелектриках, впливаючи таким чином на електричні властивості та мікроструктуру. Додавання невеликої кількості Mn компенсує дисбаланс заряду, спричиненого додаванням іонів $\mathrm{Nb}$ або інших донорів електронів. При цьому Mn сегрегується на границях зерен, на відміну від $\mathrm{Nb}$, що дифундує в середину зерен $\mathrm{BaTiO}_{3}$.

Введення в решітку іонів Mn не впливає на розмір кристалу, однак зменшує діелектричну проникність, оскільки іони Mn займають більш центральне положення, в порівнянні з іонами Ті [5].

\subsection{4. Лантан La}


Механізм допування $\mathrm{SrTiO}_{3}$ лантаном (La), очевидно, передбачає акумулювання іонів La на границях зерен, оскільки дані рентгенівського фотоелектронного спектроскопу не виявляють зміни $3 \mathrm{~d}$ стану Ті. В свою чергу зміна $3 \mathrm{~d}$ стану Ті вказувала б на зміну валентності Ті за рахунок деформації гратки внаслідок оточення Lа кисневими іонами, що свідчило б про внесення іонів La безпосередньо в решітку та заміні іонами La іонів $\mathrm{Sr}$.

\subsection{5. Кальцій Са}

Допування $\mathrm{BaTiO}_{3}$ іонами $\mathrm{Ca}$ інгібує ріст зерен під час спікання. Оскільки поведінка діелектричного параметра залежить від розміру зерен, допування призводить до розширення і сплющення максимуму діелектричної проникності.

Зазвичай введення іонів Са проводять для підвищення Тс, для розширення робочого температурного інтервалу, оскільки діелектрична проникність знижується після переходу через Тс, що відбувається за рахунок не центрового положення Са, в порівнянні з іонами Ва. В області існування твердих розчинів в точці Кюрі зміни незначні, в той час як положення низькотемпературних фазових переходів знижуються зі зростанням концентрації $\mathrm{CaTiO}_{3}$.

\subsection{6. Цирконій $\mathrm{Zr}$}

Аналогічно Сa, додавання іонів цирконію $(\mathrm{Zr})$ призводить до пригнічення росту зерна, розширення і сплющення максимуму діелектричної проникності.

При цьому всі фазові переходи відбуваються в одній температурній області. Фазові переходи розмиті внаслідок існування трьох фаз. Ступінь розмиття визначає ступінь формування кристалічної структури і розмір зерна. Допування іонами Zr ефективне не лише $з$ точки зору зміщення Тс нижче кімнатної температури, але й з точки зору значного послаблення температурної залежності діелектричної проникності. Цирконій хімічно більш стійкий, ніж Ті або інший В-вузол. Тому він сильно пригнічує провідність за рахунок механізму захоплення, що призводить до зниження втрат заряду керамічного матеріалу. Для контролю температури фазового переходу важливим є співвідношення $\mathrm{Zr} / \mathrm{Ti}$. При х $>0,08$ BTZ виявляє широку криву температурної залежності діелектричної проникності біля Тc, спричиненого неоднорідним розподілом Zr у вузлах $\mathrm{Ti} \mathrm{i} \mathrm{за} \mathrm{рахунок}$ напружень у зернах.

Окрім того, допування цирконієм впливає на порядок фазового переходу за температурою Кюрі, де перший порядок змінюється на другий при збільшенні вмісту цирконію, що є наслідком збігу температури Кюрі і температури Кюрі-Вейса.

\section{2. Методи синтезу допованого нанодисперсного порошку титанату барію}

Синтез нанопорошку із заданими характеристиками залежить безпосередньо від чистоти та особливостей структури порошку, що, в свою чергу, залежить від методу 
отримання.

Існують різні методи отримання допованого нанодисперного порошку титанату барію. Традиційний твердофазний синтез [15], незважаючи на простоту приготування, має ряд недоліків, пов'язаних 3 високими температурами процесу, що призводять до коалесценції і росту зерен, наявності вторинних фаз, а також не можливості забезпечити якісне допування, високу стехіометрію та вузький розподіл за розмірами тощо.

Натомість тонкі хімічні методи отримання нанорозмірного порошку дозволяють отримати нанорозмірні порошки 3 високою дисперсністю, чистотою, стехіометрією та можливістю якісного однорідного допування. Найбільш перспективними $є$ методи хімічного осадження [18 - 26]: золь-гель метод (3 використанням міцелярних або полімерних гелів), гідротермальний [5], метод комплексонатної гомогенізації, метод під дією мікрохвильового випромінювання, метод швидкого термічного розкладу прекурсорів в розчині тощо [16].

3 іншого боку, такі тонкі методи, як золь-гель та гідротермальний, незважаючи на безумовний ряд переваг в досягненні нанорозмірного гомогенного порошку на основі складних оксидів та можливості отримання порошків з ідеальними властивостями, мають суттєві недоліки з точки зору масштабності виробництва, наявної пористості, високої вартості реагентів та обладнання, а також значної тривалості процесу. Натомість метод співосадження дозволяє отримати стехіометричний нанорозмірний порошок 3 вузьким розподілом за розміром, 3 мінімізацією вторинної фази, 3 невисокими витратами на пристрої та обладнання, короткою тривалістю процесу, можливістю синтезу за стандартних умов та масштабністю виробництва.

Таблиця 2.

Приклади матеріалів, отриманих різними методами

\begin{tabular}{|l|l|c|}
\hline Матеріал & Метод синтезу & Джерело \\
\hline Y-doped $\mathrm{Ba}_{0,95} \mathrm{Sr}_{0,05} \mathrm{Ti}_{1-\mathrm{x}} \mathrm{O}_{38}$ & Оксалатний & 17 \\
\hline $\mathrm{Ba}_{0,80} \mathrm{~Pb}_{0,20} \mathrm{Ti}_{1-\mathrm{x}} \mathrm{Zr}_{\mathrm{x}} \mathrm{O}_{3}(\mathrm{x}=0 \ldots 0,1)$ & Твердофазний & 27 \\
\hline $\mathrm{Y}, \mathrm{Mg}$-doped $\mathrm{BaTiO}_{3}$ & Ядро-оболонка & 28 \\
\hline $\mathrm{Zr}$-doped $\mathrm{BaTiO}_{3}$ & Золь-гель & 29 \\
\hline
\end{tabular}

Діелектричні властивості залежать від методу допування. Виявлено, що найкращі діелектричні властивості при модифікуванні допантами у формі оксиду, ніж співосадженням їх солей [9].

В іншій праці елемент $\mathrm{Mn}$ краще вносити в решітку $\mathrm{Ba}\left[\mathrm{Ti}_{1-\mathrm{x}} \mathrm{Mn}_{\mathrm{x}}\right] \mathrm{O}_{3}$ у вигляді іону, ніж у формі $\mathrm{MnCO}_{3}$. Наприклад, в патенті [23] в якості джерела іонів $\mathrm{Mn}$ використовували $\mathrm{MnCl}_{2}$, який розчиняється в розчині титану та барію 3 отриманням задовільного 
співвідношення $\mathrm{Ba} / \mathrm{Ti}$, з хорошим контролем розміру частинок, що вказує на доцільність використання методу співосадження для рівномірного допування титанат барію.

Допування можна проводити наступними способами:

- додаванням допантів до процесу синтезу. При цьому потрібна найнижча відносно інших способів температура спікання, необхідна для максимальної щільності. При цьому швидкість ущільнення обумовлена наявністю рідкої фази, яка утворюється внаслідок стохіометричного дефекту Ва. Однак механізм компенсації заряду передбачає появу вакансій Ti, що сприяє швидкій дифузії і росту зерен;

- допуванням оксидами елементів вже синтезованого титанату барію. При цьому ріст зерен пригнічується і знижується температура максимальної щільності;

- хімічним співосадженням допантів на синтезованому титанаті барію. Метод дозволяє отримати найвищу щільність за рахунок кращого розподілу допантів на границях зерен, однак для даного процесу необхідна вища температура та час спікання) [9].

Кількість успішних синтезів, допованих нанопорошків $\mathrm{BaTiO}_{3}$, вкрай низька i обмежена, що пов'язано з низькою стехіометрією отриманих структур та нерівномірним розподілом допантів, тому дане питання потребує детального розгляду та дослідження.

В останні роки привертає увагу метод так званого «ядро-оболонка» (core-shell) за свої розширені можливості, який дозволяє отримати двофазний компонент, що містить кристалічне ядро, аморфну оболонку і має схожий склад. У випадку допування ВТ ніобієм утворюється аналогічна зонально-оболонкова структурна технологія, яка за рахунок утворення ядра ВТ та шару на основі розчину ВТ і допанту, інгібує ріст зерен за рахунок оболонки, а за рахунок гетерогенності забезпечує розмитий фазовий перехід [1]. Однак, елементи, доповані таким чином, не входять у склад внутрішньої решітки, а також оболонка не тільки гальмує ріст зерен, але й знижує суттєво діелектричну проникність..

У роботі [30] описаний одноступінчатий процес core-shell методом вологої хімії 3 допомогою ультразвуку. Однак порошок, отриманий даним методом, має доволі великі розміри.

3 точки зору продуктивності, стехіометрії, простоти, швидкості процесу, економічності найкращим методом для синтезу допованого нанопрошку $\epsilon$ метод співосадження, при якому з розчину з певними елементами осаджується відповідний комплекс.

Основними проблемами даного синтезу $є$ нерівномірний розподіл елементівдопантів у структурі титанату барію, наявність вторинних фаз, неодночасне осадження елементів у варіанті оксалат-методу, тривалості та собівартості процесу тощо. 


\section{Висновки}

Останнім часом особливої уваги заслуговують сегнетоелектрики-релаксори 3 розмитим фазовим переходом. 3 метою зміщення температури фазового переходу та згладження кривої температурної залежності діелектричної проникності порошок титанату барію допують різними елементами. В якості ізовалентних іонів вводять іони $\mathrm{Zr}(\mathrm{IV}), \mathrm{Ca}(\mathrm{II})$ у вузли Ti та Ва відповідно, а в якості гетеровалентних іонів, головним чином, вводять оксиди рідкоземельних елементів, зокрема, іони $\mathrm{Nb}(\mathrm{V}), \mathrm{Y}$ (III), які також пригнічують ріст зерен титанату барію. У вузли катіону Ва додекаедра в якості допанту можна вводити іони $\mathrm{Co}^{2+}, \mathrm{La}^{3+}, \mathrm{Ce}^{3+}, \mathrm{Sr}^{2+}, \mathrm{Y}^{3+}$. В локації катіону Ті октаедру можна вводити іони $\mathrm{Nb}^{5+}, \mathrm{Ce}^{3+}, \mathrm{Sb}^{5+}, \mathrm{Ta}^{5+}, \mathrm{Al}^{3+}, \mathrm{Y}^{3+}$. Дисбаланс заряду, спричинений гетерогенним заміщенням іонів донорами, можна усунути шляхом додавання акцепторів, які захоплюють вільні електрони і таким чином забезпечують електронейтральність решітки.

Рівномірний розподіл елементів у структурі залежить безпосередньо від методу отримання допованого нанодисперсного порошку титанату барію. Серед найбільш перспективних тонких хімічних методів отримання допованого нанопорошку титанату барію найбільш доцільним, з точки зору стехіометричності, економічності, відсутності вторинної фази, короткої тривалості процесу та продуктивності є метод осадження.

\section{Перелік посилань}

1. Б.А. Ротенберг. Керамические конденсаторные диэлектрики // СПб. : Тип. ОАО НИИ "Гириконд" ; СПб. : РФФИ, 2000. - 245 с. : ил. - Библиогр.: С. 228-245. - 70.00 р.

2. Giada Graziana Genchi, Attilio Marino, Antonella Rocca, Virgilio Mattoli and Gianni Ciofani. Barium titanate nanoparticles: promising multitasking vectors in nanomedicine. Nanotechnology 27 (2016) 232001 (19pp) 2016 IOP Publishing Ltd Printed in the UK

3. A. Peláiz-Barranco, F. Calderón-Piñar, O. García-Zaldívar and Y. González-Abreu. Relaxor Behaviour in Ferroelectric Ceramics // "Advances in Ferroelectrics”,2012.

4. Dielectric properties of A- and B-site doped $\mathrm{BaTiO}_{3}$ ( I ): La - and Al-doped solid solutions J. Appl. Phys. 97, 074105 (2005); 10.1063/1.1879074

5. T.Sahoo, G.K. Pradhan, M.K. Rath, B. Pandey,. Characterization and photoluminescence studies on hydrothermally synthesized Mn-doped barium titanate nanopowders // Materials Letters (2007).

6. M.M. Vijatović Petrović, J.D. Bobić, R. Grigalaitis, Donor-acceptor joint effect in barium titanate systems// Ceramics International, vol. 41, 2015, pp. 11365 - 11371. 
7. S.Suasmoro, E.Hastuti, D.Darminto. Defect analysis of Y3+-doped Ba0,95Sr0,05Ti1-xO3 $\delta$ above Curie temperature // Ceramics International, pp. 315 - 320, 2007.

8. L.Padilla-Campos, D.E.Diaz-Droguett, R.Lavin, S. Fuentes. Synthesis and structural analysis of Co-doped BaTiO3 // Journ.of.Molecular Structure (2015).

9. J.F.Fernandez,P.Duran,C.Moure. Influence of the Doping Method on X7R Based-BaTiO3 Capacitors// Journal Ferroelectrics. 1992, vol. 127, pp. 47 - 52.

10. Minjia Wang; Qilong Zhang; Xinhui Zhao; Hui Yang. Dielectric Properties and Microstructure of Y-Al-Ga-Si Co-Doped Barium Titanate Ceramics//Key Engineering Materials; Vol. 602 603, P. 700. - 2014.

11. Zhengbo Shen; Xiaohui Wang; Huiling Gong; Longtu Li. Structural and Dielectric properties of Rare Earth (Y, Ho) Doped Ba0.95 Ca0.05 Ti0.85 Zr0.15O3 Ceramics//Key Engineering Materials;2014, Vol. 602-603, P. 7281.

12. Jong-Seo Park, Yun-Hee Lee, Ki-Bok Kim, Yong-Il Kim. Structural study of Ca doped barium titanate// Nuclear Instruments and Methods in Physics Research Section B: Beam Interactions with Materials and Atoms. - Vol. 284, P. 44-48. - 2012

13. Marco Deluca, Catalina A. Vasilescu, Adelina CInvestigation of the composition-dependent properties of $\mathrm{BaTi}_{1}-\mathrm{XZrxO}_{3}$ ceramics prepared by the modified Pechini method// Journal of the European Ceramic Society. - vol. 32, pp. 3551 - 3566. - 2012.

14. X.G.Tang, K.-H Chew, H.L.W.Chan/ Diffuse phase transition and dielectric tenability of $\mathrm{Ba}\left(\right.$ ZryTi1-y)O $\mathrm{O}_{3}$ relaxor ferroelectric ceramics. - 2004

15. Jing Zhi, Ang Chen, Yu Zhi, Paula M.Vilarinho. Incorporation of Yttrium in Barium Titanate Ceramics // Journal of the American Ceramic Society. - 1999.

16. Гусева А.Н. Методы получения наноразмерных материалов// Курс лекций: Екатеринбург, 2007.

17. K. Albertsen, D. Hennings, O. Steigelmann. Donor-Acceptor Charge Complex Formation in Barium Titanate Ceramic // Journal of Electroceramics (1998) 2: 193. doi:10.1023/A:1009926916939.

18. Chemical Preparation of Barium-Strontium Titanate/ Taeyong Noh, Seungwon Kim, Chul Lee // Bull. Korean Chem. Soc. - 1995. - Vol. 16, No. 12. - P.1180 - 1184

19. В. М. Погибко, В. В. Приседский, И. Л. Сидак, Н.Г. Кисель. Механизм и кинетика синтеза нанодисперсных порошков перовскитов из оксалатных прекурсоров // Наносистеми, наноматеріали, нанотехнології. - 2012. - Т. 10, Вип. 2. - С. 321-333. - 2010.

20. H.S. Potdar, S.B. Deshpande. Simplified chemical route for the synthesis of barium titanyl oxalate // International Journal of Inorganic Materials: 613-623, 2001. 
21. Fu-Su Yen, Chen T. Chang,Yen-Hwei Chang. Characterization of Barium Titanyl Oxala te Tetrahydra te // Journal of the American Ceramic Society, 1990.

22. L M Arunachalam, D Chakravorty, E C Subbarao. Synthesis and properties of manganesedoped barium titanate// Mater. Sci. (1987) 9: 159. doi:10.1007/ BF02744264.

23. Kang Heon Hur, Jai Joon Lee. Method for preparing barium titanate powder by oxalate synthesis // Pub.No.: US 2003/0133869.

24. Donald Keith Swanson. Method of making barium titanate// US7001585 B2,-2003.

25. Gijp Sven. Preparation of homogeneously-doped barium titanate// ISBN: 90-36511798, 1999.

26. Taeyong Noh, Seungwon Kim. Chemical Preparation of Barium-Strontium Titanate // Korean Chem. Soc, 1995.

27. P.Kumar. Synthesis and dielectric properties of substituted barium titanate ceramics. Journal of Alloys and Compounds, 489 (2010), P. 59 - 63.

28. Chang-Hoon Kim, Kum-Jin Park, Yeo-Joo Yoon, Kang-Heon Hur. Role of Yttrium and Magnesium in the Formation of Core-shell Structure of BaTiO3 Grains in MLCC // Journal of the European Ceramic Society.- 28(6): 1213-1219, 2008.

29. M.Aghayan, A. Khorsand Zak, M. Behdani, A. Manaf Hashim. Sol-gel combustion synthesis of $\mathrm{Zr}$-doped $\mathrm{BaTiO}_{3}$ nanopowders and ceramics: Dielectric and ferroelectric studies // Ceramics International, 2014.

30. Rouholah Ashiri R. Ashiri. Obtaining novel crystalline/amorphous core/shell structure in the barium titanate nanocrystals by an innovative one-step approach // RSC Adv., 2015, DOI: 10.1039/C5RA05406K. 